\title{
Original
}

\section{Enhancement of Epidermal Growth Factor Receptor-degradation Pathway in Acquired Gefitinib-resistant Human Non-small Cell Lung Cancer Cell Lines}

\author{
Toshimitsu YAMAOKA ${ }^{1,2,6)}$, Tohru OHMORI ${ }^{1,3)}$, Fumiko INOUE ${ }^{3)}$, \\ Tsuyoki KADOFUKU ${ }^{3}$, Koichi ANDO ${ }^{1)}$, Hiroo IsHIDA ${ }^{1)}$, \\ Takamichi HosaKA ${ }^{1}$, Takao ShIRAI ${ }^{1}$, Masanori MATSUdA ${ }^{1}$, \\ Munehide Noda ${ }^{1)}$, Takashi HIRose ${ }^{1)}$, Naoya HorichI ${ }^{1)}$, \\ Kazuto Nishio ${ }^{4)}$, Nagahiro SAIJO ${ }^{5)}$, Carlos L. Arteaga ${ }^{6)}$, \\ Toshio KUroki ${ }^{7)}$, Mitsuru Adachi ${ }^{1)}$ and Takeshi KaWaguchi ${ }^{2)}$
}

\begin{abstract}
The epidermal growth factor receptor (EGFR) is highly expressed in a range of tumor types, and has been implicated in several aspects of tumor survival and growth, such as cell proliferation, apoptosis, angiogenesis, and metastasis. Gefitinib ('Iressa', ZD1839), an orally active EGFR-TKI (EGFR tyrosine kinase inhibitor), is clinically used in patients with non-small-cell lung cancer (NSCLC). Because this drug is continuously administered until recurrence of the disease or treatment is stopped for other reasons, clinical drug resistance might develop during long-term exposure. To elucidate the mechanism(s) of resistance to gefitinib, we established gefitinib-resistant NSCLC cell lines using a stepwise-dose escalation method. This resistant cell line, PC-9/ZD201 had a 3- to 4-fold increase in resistance to gefitinib compared to parental PC-9 cells. After more than 6 months of culturing in drug-free conditions, PC-9/ZD201 regained sensitivity to gefitinib, this revertant cell line was named PC-9/ZD201R. In PC-9/ZD201 cells, EGFR mRNA and protein expression levels decreased to less than $50 \%$ of those in PC-9 cells. In PC-9/ZD201R cells, EGFR protein but not mRNA expression partially recovered. After $2 \mathrm{hrs}$ exposure to $100 \mathrm{ng} / \mathrm{ml}$ Transforming Growth factor $\alpha$ (TGF- $\alpha)$, EGFR protein expression was significantly decreased in resistant cells but not in the parental PC-9 cell line. This decrease in EGFR expression was completely inhibited by lactacystin, a 26S proteasome inhibitor. To determine EGFR-degradation activity in gefitinib-resistant cell lines, EGFR-internalization assays and -degradation assays were performed using ${ }^{125}$ I-EGF. EGFR-internalization and -degradation activities were increased about 2 fold in PC-9/ZD201 compared to PC-9 and PC-9/ZD201R cell lines. In intrinsic gefitinib-resistant PC-14 cells, EGFR-degradation was more than
\end{abstract}

\footnotetext{
1) First Department of Internal Medicine, Showa University School of Medicine, 1-5-8, Hatanodai, Shinagawa-ku, Tokyo 142-8555, Japan.

2) Department of Public Health, Showa University School of Medicine.

${ }^{3)}$ Institute of Molecular Oncology, Showa University School of Medicine.

4) Shien Laboratory, National Cancer Center Hospital, Pharmacology Division, National Cancer Center Research Institute.

5) Internal Medicine, National Cancer Center Hospital, Pharmacology Division, National Cancer Center Research Institute.

6) Vanderbilt-Ingram Cancer Center, Vanderbilt University School of Medicine.

7) School of Medicine, Gifu University.
} 
5-fold higher than in PC-9 cells. These results suggest that the EGFRubiquitylation and -degradation pathways contribute to the development of gefitinib-intrinsic, and -acquired resistance in NSCLC cells.

Key words: EGFR, tyrosine kinase inhibitor, acquired resistance, gefitinib, non-small cell lung cancer, c-Cbl, ubiquitin

\section{Introduction}

The epidermal growth factor receptor (EGFR/HER1/erbB1) is a 170-kDa cell membrane glycoprotein with tyrosine kinase activity, which has been shown to play central roles in cell proliferation, cell survival, migration, differentiation and angiogenesis ${ }^{1,2)}$. EGFR-mediated signaling is thought to play an important role in the progression of epithelial neoplasms and increased EGFR expression has been reported in wide variety of human tumors ${ }^{3}$. Moreover, increased EGFR expression is associated with advanced tumor stage, resistance to standard therapies and poor patient prognosis ${ }^{4-7)}$. The oncogenic potential of EGFR and its high levels of expression in tumor tissues provide a rationale for targeting this oncoprotein with novel molecular therapeutics. Recent studies demonstrate that ligand-activated EGFR is strongly coupled to the c-Cbl adaptor protein, an E3 ubiquitin ligase, which recruits ubiquitin-loaded E2 enzymes. This ubiquitylation signaling mediates receptor endocytosis and internalization, and subsequently EGFR is targeted for lysosomal degradation ${ }^{8-11)}$. This process is thought to have an important role in the termination of EGFR signaling ${ }^{12)}$. Although EGFR-degradation is a well-known phenomenon, the major role of the EGFR degradation pathway in cancer cell biology is still unclear.

Gefitinib ['Iressa',4-(3-chloro-4-fluorophenylamino)-7-methoxy-6( 3-(4-morphlinyl)propoxy)quinazoline] is an orally active EGFR-TK inhibitor (EGFR-TKI) that blocks signal transduction pathways implicated in cancer cell proliferation, survival and other hostdependent processes promoting cancer growth. Recently, this drug has been used to treat patients with relapsed or recurrent non-small-cell lung cancer (NSCLC), and its clinical efficacy has been confirmed ${ }^{13-15)}$. Gefitinib is administered using a once-daily oral dosing regimen, and it is possible that clinical resistance may develop following long-term exposure. The development of resistance to anticancer agents is a major limitation of cancer chemotherapy. In order to elucidate a mechanism of resistance to gefitinib, we have established acquired gefitinib-resistant NSCLC cell lines by continuous exposure to the drug for more than 2 years, using a stepwise-dose escalation method in vitro. In this paper, we describe decreased EGFR expression and enhancement of EGFR-degradation activity in the resistant cells established at a relatively early time after drug exposure.

\section{Materials and Methods}

\section{Chemicals and antibodies}

Gefitinib ("Iressa") was donated by AstraZeneca (Wilmington DE, UK). Anti-phosphotyrosine antibody (PY 20) was purchased from Transduction Lab. (Lexington, KY). Other antibodies were purchased from Santa Cruz Biotech. (SantaCruz, CA). Other chemicals were purchased from Sigma (St. Louis, MO), if not otherwise mentioned.

Establishment of gefitinib-resistant cell lines PC-9 and PC-14 human non-small cell lung 
cancer cell lines were established from tissue from an untreated patient, kindly donated by Prof. K. Hayata (Tokyo Medical College). Both cell lines were cultured in RPMI1640 medium supplemented with $10 \%$ fetal calf serum (FCS) and maintained in a $5 \% \mathrm{CO}_{2}$ incubator at $37^{\circ} \mathrm{C}$ with humidified conditions.

For the establishment of gefitinib-resistant cell lines, PC-9 cells were continuously exposed to stepwise dose escalation of gefitinib for more than 1 year. A resistant cell line which survived in $200 \mathrm{nM}$ gefitinib-containing medium was cloned and named PC-9/ZD201. This cell line was maintained by culturing in $200 \mathrm{nM}$ gefitinib-contained medium. The resistant cells were cultured with drug-free medium at least for 2 weeks before all of the experiments. Because the relative resistant value of the cell line was stable for at least 3 months after culturing in drug-free conditions (data not shown), the cells were used for experiments during this period. Culture in gefitinib-free conditions for more than 6 months restored the sensitivity of PC-9/ZD201 cells to gefitinib, subsequently established as a revertant cell line, PC-9/ZD201R.

\section{Total RNA isolation and PCR quantification}

Total RNA was isolated using the guanidium isothiocyanate method using RNeasy mini kit (QIAGEN) according to the manufacturer's instructions. After RNA isolation, cDNA was prepared in the presence of random 9 mers using Takara RT-PCR Kit (Takara).

Quantification of EGFR was done using a fluorescence-based real-time detection method (GeneAmp 5700 sequence detection system ; Perkin-Elmer Applied Bio). Cycling conditions were 40 cycles at $94^{\circ} \mathrm{C}$ for $20 \mathrm{sec}, 55^{\circ} \mathrm{C}$ for $20 \mathrm{sec}$ and $72^{\circ} \mathrm{C}$ for $30 \mathrm{sec}$. cDNA levels during the linear phase of amplification were normalized against $\beta$-actin controls. Three sets of EGFR PCR primers were used as follows; No. 1 forward: 5'-GGAAATTACCTATGTGCAGAGG-3', reverse : 5'-CCTTTAATGGATACACGTCT-3', position : 187 to 403, No. 11 forward : 5'-ACGAATGGGCCTAAGATC-3', reverse : 5'-TGCTTACCCGGATTCTAGG-3', position : 1913 to 2117 , No. 16 forward : 5'-TGCTGGGTGCGGAAGAGAAA-3', reverse : 5'-ACGACCCACGCCTTCTCTTT-3', position : 2768 to 3014. No. 1 and No.11 primer sets amplify sequences in the extra-cellular domains and No. 16 amplifies EGFR intra-cellular domain sequence. The $\beta$-actin primer set was; forward: 5'-CCTGGCACCCAGCACAAT3', reverse : 5'-GGGCCGGACTCGTCATAC-3' The c-Cbl PCR primer set was ; forward : 5'CGCTAAAGAATAGCCCACCTTAT-3', reverse : 5'-ATGGCCTCCAGCCCAGAACTGAT3', position : 149 to 813 .

\section{Immunoblot analysis}

Cells were washed with twice with ice-cold PBS and then lysed by EBC buffer $(50 \mathrm{mM}$ Tris- $\mathrm{HCl}, \mathrm{pH} 8.0,120 \mathrm{mM} \mathrm{NaCl}, 0.5 \%$ Nonidet $\mathrm{P}-40,100 \mathrm{mM} \mathrm{NaF}, 200 \mathrm{mM} \mathrm{Na}$ orthovanadate, and $10 \mathrm{mg} / \mathrm{ml}$ of leupeptin, aprotinin and PMSF) using an ultrasonic disrupter (Tomy, Japan). The cell lysate was precleared by centrifugation, resolved by $10 \%$ SDS-PAGE, transferred to nitrocellulose membrane, and probed with respective antibodies. Bound antibodies were detected with horseradish peroxidase-linked Ig (Amersham) and ECL reagents (NEN Life Science).

\section{Ligand binding analysis}

To measure ligand binding to the cell surface, cells were treated with $2 \mathrm{ng} / \mathrm{ml}{ }^{125} \mathrm{I}$-EGF 
(Amersham) in ice-cold RPMI1640 for $1 \mathrm{~h}$ then washed three times with ice-cold PBS. The labeled cells were lysed with $0.1 \mathrm{~N} \mathrm{NaOH}$ solution containing $0.1 \%$ SDS, and the radioactivity was determined. Nonspecific binding was calculated by performing the binding assays in the presence of a 100-fold excess of unlabeled ligand.

\section{Ligand internalization assay and degradation assay}

Receptor EGF internalization analysis and degradation assay was basically performed as described previously ${ }^{9,16,17)}$. Briefly, cells on ice were exposed to $2 \mathrm{ng} / \mathrm{ml}{ }^{125}$ I-EGF (Amersham) for $1 \mathrm{~h}$. Then the cells were washed once in ice-cold RPMI1640 containing $0.1 \%$ FCS. The cells were resuspended in RPMI 1640 containing 10\% FCS and incubated for indicated time periods at $37^{\circ} \mathrm{C}$. The cellular distribution of the radiolabeled ligand was determined by using a 7 min-long incubation in $0.5 \mathrm{ml}$ of acid wash buffer $(0.2 \mathrm{M}$ sodium acetate, $0.5 \mathrm{M} \mathrm{NaCl}, \mathrm{pH} 4.5$ ). The released ligand was considered to be cell surfaceassociated ligand. The remaining radioactivity was solubilized in $100 \mathrm{mM} \mathrm{NaOH}$ solution containing $0.1 \%$ SDS and was considered to be internalized ligand. The internalization index was calculated using the following formula :

Internalization index $=$ internalized radioactivity $/($ surface-associated + internalized radioactivity)

For the ligand degradation assay, the cells were treated with radiolabeled ligand as above with/without $0.2 \mathrm{mM}$ chloroquine disphosphate; a lysosomal inhibitor. After the incubation, the samples were solubilized with $1 \%$ SDS and trichloroacetic acid (TCA) (10\% final concentration) was added. After the treatment, the samples were precipitated by centrifugation at $4{ }^{\circ} \mathrm{C}$. Radioactivity present in the supernatants and pellets (TCA-insoluble fraction) was measured by a gamma counter (Fig. 1). The EGF-degradation activity was

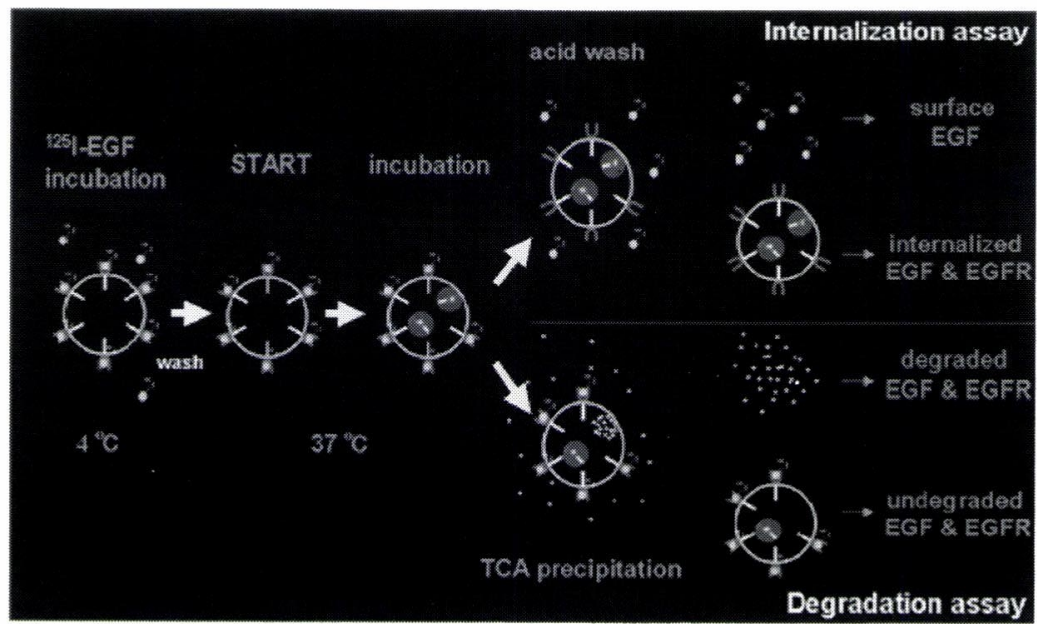

Fig. 1. Schematic view of EGF-internalization and -degradation activity assay Cells were exposed to $2 \mathrm{ng} / \mathrm{ml}{ }^{125} \mathrm{I}$-EGF for $1 \mathrm{~h}$ at $4{ }^{\circ} \mathrm{C}$. The cells were then washed once and resuspended with normal medium at $37^{\circ} \mathrm{C}$. After incubation for indicated time periods (1), cells were washed with acid wash buffer to dissociate surface-bound EGF from internalized EGF; internalized assay (2), cells were solubilised with $1 \%$ SDS and treated with trichloroacetic acid (TCA) (10\% final concentration) to dissociate degraded EGF from intact EGF; degradation assay. 
calculated using the following formula :

EGF-degradation $(\%)=$ supernatant radioactivity $/($ supernatant + pellet radioactivity $)$

\section{Statistical analysis}

Statistical analysis of real-time PCR data was performed using Stat View II (Abacus Concepts, Berkeley, CA). Data was expressed as the mean \pm SE. Statistical differences were calculated by ANOVA using Fisher's protected least significant difference test.

\section{Results}

\section{Established of acquired gefitinib-resistant cell lines}

To elucidate the mechanisms of acquired resistance to gefitinib, resistant NSCLC cell lines were established by continuous exposure to gefitinib using the stepwise dose escalation method. Resistance to gefitinib developed slowly; the relative resistant values reached 3 to 4 fold after more than 6 months exposure of the drug. For these experiments a clone of the gefitinib-resistant cell line, named PC-9/ZD201, which was able to survive in $200 \mathrm{nM}$ gefitinib-containing medium, was used. Sensitivities to gefitinib in these cell lines were measured by MTT assay. The IC50 value of gefitinib in PC-9 cells was $53.2 \mathrm{nM}$. The gefitinib-resistant cell line, PC-9/ZD201 showed about 3-fold higher resistance to gefitinib $($ IC50 $=133.9 \mathrm{nM})$ than PC-9 cells (Fig. 2). The sensitivity to gefitinib was completely restored in PC-9/ZD201R cells. On the other hand, IC50 value of gefitinib in PC-14 NSCLC cell line was approximately $20 \mu \mathrm{M}$ (data not shown). We used PC-14 cells as an intrinsic gefitinib-resistant cell line.

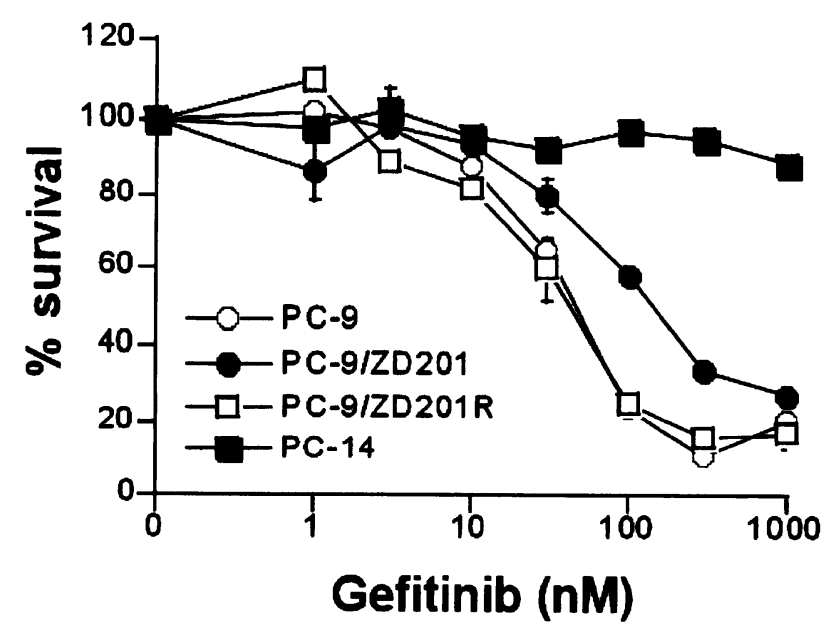

Fig. 2. Cytotoxic effect of gefitinib on gefitinib-resistant non-small cell lung cancer cell lines

The cells were continuously treated with gefitinib for 4 or 5 days. Growth inhibition was analyzed using a MTT assay. The IC50 values of gefitinib in PC-9, PC-9/ZD201 and PC-9/ZD201R cells were $53.2 \mathrm{nM}, 133.9 \mathrm{nM}$, and $51.9 \mathrm{nM}$, respectively. The IC50 value of gefitinib in PC-14 was approximately $20 \mu \mathrm{M}$ (data not shown, as it was off scale). Data represented is mean \pm SD (bar) of three separate experiments, each performed in triplicate. 


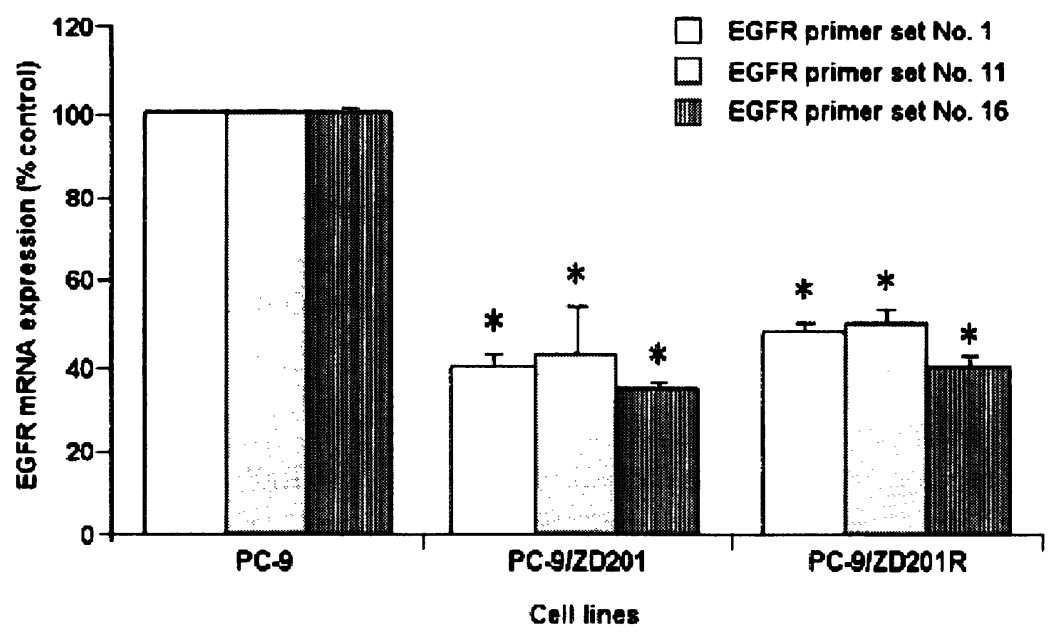

Fig. 3. Expression of EGFR mRNA in gefitinib-resistant cell lines Expression of EGFR mRNA was measured by real-time PCR. EGFR mRNA expression was measured using 3 sets of primers No. 1, No. 11 and No. 16. $\beta$-actin was used as the internal-control primer; forward: 5'-CCTGGCACCCAGCACAAT3', reverse : 5'-GGGCCGGACTCGTCATAC-3'. Data represented means \pm SD (bar) of three separate experiments. Statistical differences were calculated by ANOVA with Fisher's protected least significant difference test.

\section{Expression levels of EGFR $m R N A$ and protein}

EGFR mRNA expression was analyzed by quantitative real-time PCR in these cell lines using 3 sets of the primers (No. 1, No.11, and No. 16). In PC-9/ZD201 cells, the expression level of EGFR mRNA was significantly decreased $(\mathbf{P}<0.05$; Wilcoxon test $)$ to 35 to $40 \%$ of that in parental cells (Fig. 3). In PC-9/ZD201R cells, the EGFR mRNA expression was almost the same as that of PC-9/ZD201 cells.

EGFR protein expression levels were analyzed by Western blotting analysis using a specific anti-EGFR antibody. The expression of EGFR protein was significantly decreased in PC-9/ZD201 and but partially recovered in the revertant (Fig. 4a). In order to examine the influence of EGFR-ligand on the EGFR expression, cells were incubated with media containing $100 \mathrm{ng} / \mathrm{ml}$ (Transforming Growth factor) TGF- $\alpha$ for $2 \mathrm{~h}$. In all cell lines, tyrosine phosphorylation levels of EGFR were enhanced by the ligand. Interestingly, EGFR expression was significantly decreased by TGF- $\alpha$ exposure in the PC-9/ZD201 cell line. Because this decrease was inhibited by $100 \mathrm{nM}$ gefitinib, it was thought that the downregulation of EGFR expression correlated with EGFR autophosphorylation. The same phenomenon was observed in part in PC-9/ZD201R, but not in PC-9 and PC-14 cells. EGFR mRNA expression levels were not altered by TGF- $\alpha$ treatment in any of the cell lines (data not shown).

It has been reported that ligand binding to EGFR enhances endocytosis of the ligand-receptor complex and promotes degradation of the receptor ${ }^{18,19)}$. To inhibit the degradation pathway, PC-9/ZD201 cells were pretreated with $1 \mu \mathrm{M}$ of lactacystin, a 26S proteasome inhibitor, for $12 \mathrm{~h}$, following exposure to TGF- $\alpha$ and gefitinib for $2 \mathrm{~h}$. Since lactacystin completely inhibited the decrease in EGFR protein, ligand-mediated down 
a

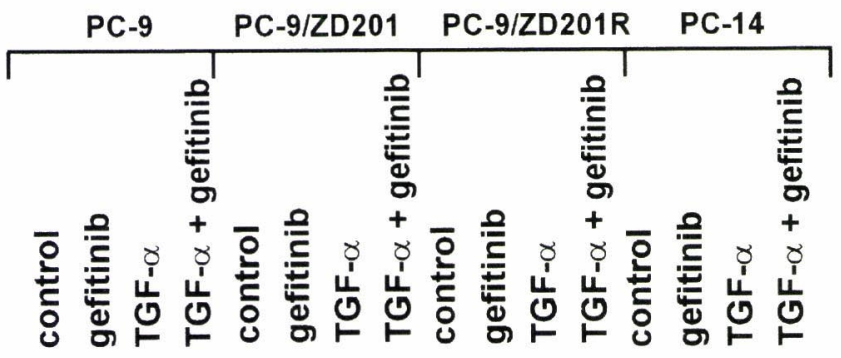

EGFR

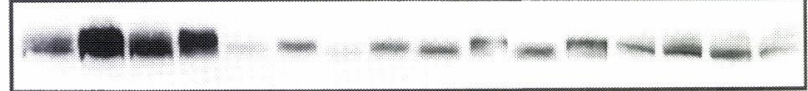

PY20

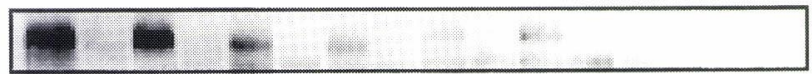

b TGF- $\alpha(100 \mathrm{ng} / \mathrm{ml})$ gefitinib (100 nM)

lactacystin (1 mM)

\section{EGFR}

Fig. 4. Expression of EGFR protein and effect of EGFR-autophosphorylation status on its turnover in gefitinib-resistant cell lines

a: Cells were treated with indicated drugs for $2 \mathrm{~h}$. Equivalent amounts of protein from each cell lysate was resolved by $10 \%$ SDS-PAGE, transferred to nitrocellulose, and Western blot analysis was performed using an anti-EGFR antibody. After EGFR detection, the membrane was stripped and reprobed with an antiphospho tyrosine (PY20) antibody.

b : PC-9/ZD201 cells were pretreated with $1 \mu \mathrm{M}$ of lactacystin, a 26S proteasome inhibitor, for $12 \mathrm{~h}$. After treatment, cells were exposed to TGF$\alpha$ and gefitinib as above.

regulation of EGFR was thought to be due to the EGFR-endocytosis and degradation pathway (Fig. 4b).

\section{EGF-binding activity}

For the purpose of measuring EGFR-turnover, EGF-binding activity was measured in these cell lines. ${ }^{125} \mathrm{I}-\mathrm{EGF}$ binding activities in PC-9, PC-9/ZD201, PC-9/ZD201R, PC-14 cells were $1864.0 \pm 65.2, \quad 1024.3 \pm 20.0,1423.8 \pm 72.9,448.2 \pm 51.6$ c.p.m $/ \mathrm{mg}$ protein, respectively (Fig. 5). In accordance with the results for EGFR protein expression, the ligand binding activity in PC-9/ZD201 was decreased to $55 \%$ of that in PC-9 and this activity was partially recovered $(76.4 \%)$ in the revertant cells. In the intrinsic gefitinibresistant PC-14 cells, the binding activity was significantly lower than PC-9 $(24.0 \%)$.

\section{EGF internalization and degradation activity}

Since ligand-mediated EGFR down regulation was observed in gefitinib-resistant cells but 


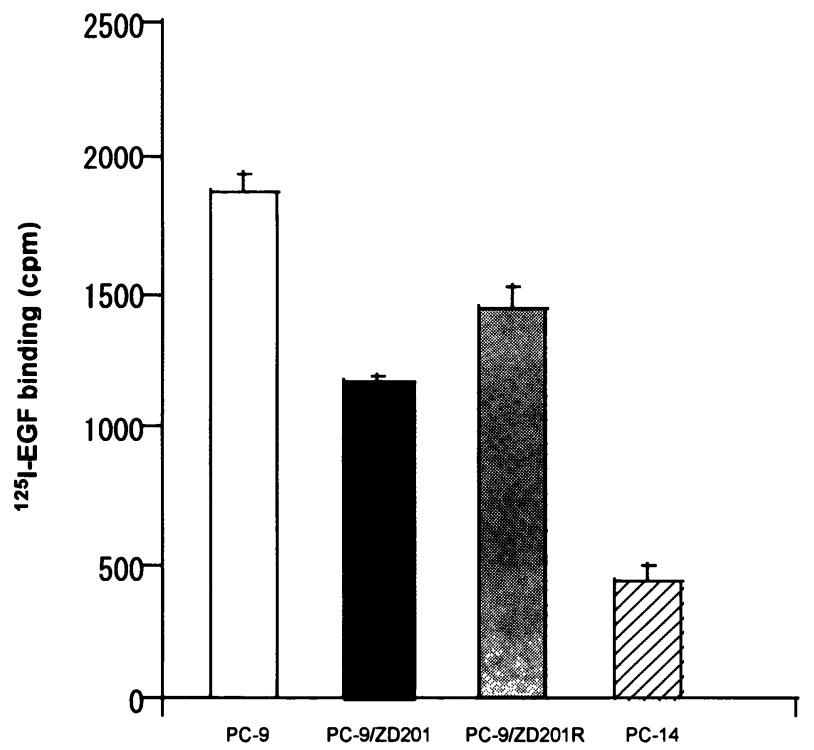

Fig. 5. ${ }^{125} \mathrm{I}-\mathrm{EGF}-\mathrm{binding}$ activity in gefitinib-resistant cell lines Cells were treated with $2 \mathrm{ng} / \mathrm{ml}{ }^{125} \mathrm{I}-\mathrm{EGF}$ (Amersham) in ice-cold RPMI1640 for $1 \mathrm{~h}$. The cells were washed three times with ice-cold PBS. The labeled cells were lysed with $0.1 \mathrm{~N} \mathrm{NaOH}$ solution containing $0.1 \%$ SDS, and the radioactivity was measured with a gamma counter. Nonspecific binding was calculated by performing the binding assays in the presence of a 100-fold excess of unlabeled ligand. Data represents means $\pm \mathrm{SD}$ (bar) of three separate experiments.

not in the parental cell line, it was expected that EGFR-internalization and -degradation pathways were altered in PC-9/ZD201 cells. To compare the EGF-internalization and -degradation activities in these cells, several kinetic assays were performed using ${ }^{125}$ I-EGF.

The short-term ligand internalization assay confirmed the relatively rapid internalization rate of ${ }^{125} \mathrm{I}$-EGF in PC-9/ZD201 cells (Fig. 6a). After 20 minutes incubation, the internalization activity increased by $37.5 \%$ in PC-9/ZD201 compared with PC-9 cells. In PC-9/ZD201R cells, internalization activity decreased to the same level of that in PC-9 cells. In the EGF-degradation assay, about $10 \%$ of EGF was catabolized in PC-9 (Fig. 6b) at 120 min after the incubation, and this was inhibited by $200 \mu \mathbf{M}$ of chloroquine, an inhibitor of lysosomal hydrolase (Fig. 6c). In agreement with the internalization assay, EGFdegradation was about 1.5-fold higher in PC-9/ZD201 and it was completely reconstituted in PC-9/ZD201R. In PC-14 cells, EGF-internalization and -degradation were significantly activated compared with PC-9 cells, by about 2 fold and 5 fold, respectively.

In order to elucidate the effect of gefitinib on EGF metabolism, the EGF-degradation assay was performed in the presence of $1 \mu \mathrm{M}$ of gefitinib. Gefitinib significantly inhibited EGF-degradation in PC-9, PC-9/ZD201, and PC-9/ZD201R cells. There was no significant difference in the inhibition ratio in these cell lines. EGF-degradation was not inhibited by gefitinib in PC-14 cells.

It has been reported that ligand binding to EGFR enhances endocytosis of the ligand-receptor complex ${ }^{16)}$ and attenuates EGFR-mediated signal transduction by its 

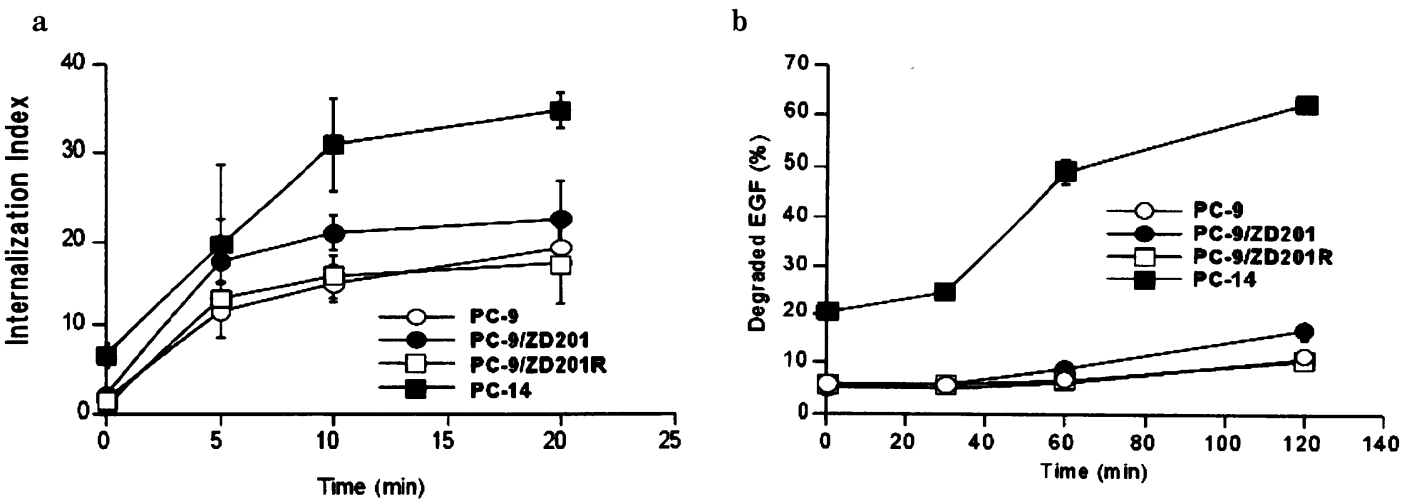

c

PC-9
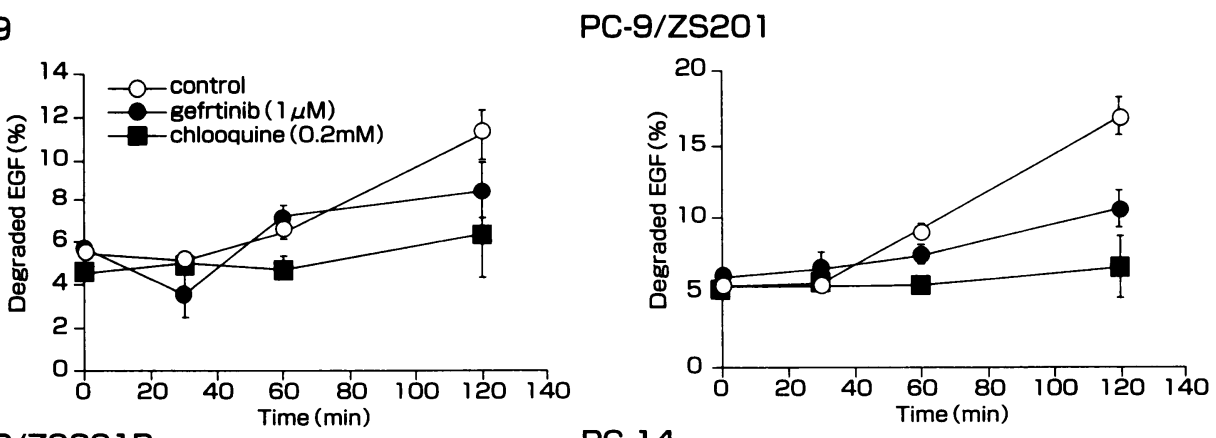

PC-9/ZS20IR

PC-14
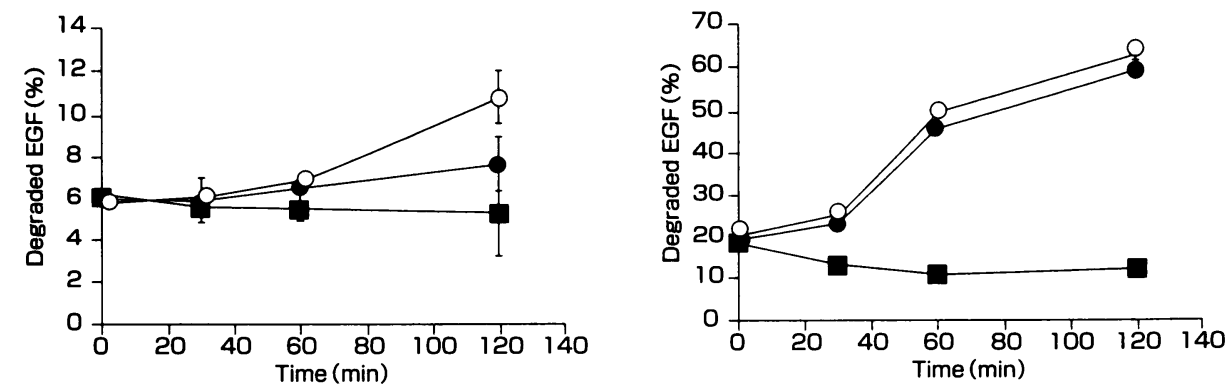

Fig. 6. EGF-internalization and -degradation activity analysis

EGF-internalization and -degradation activity assays were performed as described in Fig. 1. Cells were pretreated with ${ }^{125}$ I-EGF (Amersham) as described in the ${ }^{125}$ I-EGF-binding assay.

a : EGF-internalization activity analysis; After incubation at $37^{\circ} \mathrm{C}$ for the indicated time periods, cells were acid-washed to remove surface-bound EGF. Radioactivity present in the acidic fraction (surface-associated ligand) was assayed in triplicate. The remaining cell-associated radioactivity (internalized) was similarly quantified following cell solubilization. The ratio obtained at each time point is shown as the mean \pm SD.

b : EGF-degradation activity analysis; After incubation at $37^{\circ} \mathrm{C}$ for the indicated time periods, cells were solubilised by $1 \%$ SDS. Trichloroacetic acid (TCA) was added and the TCA-soluble fractions (degraded ligand presented) were separated from the TCA-insoluble fractions (intact ligand presented) by centrifugation. The radioactivity of both fractions was measured. The ratio obtained at each time point is shown as the mean \pm SD (bar) of three separate experiments.

c : Effect of gefitinib and chloroquine on EGF-degradation activity; Cells were pretreated with gefitinib (1 $\mu \mathrm{M})$ or chloroquine $(0.2 \mathrm{mM})$ for $1 \mathrm{~h}$ at $4^{\circ} \mathrm{C}$ when the radiolabeled ligand was exposed. After washing, cells were resuspended in normal medium in the presence of same concentrations of drugs. After incubation for the indicated time periods, the degraded-EGF was measured and represented as above (b). 


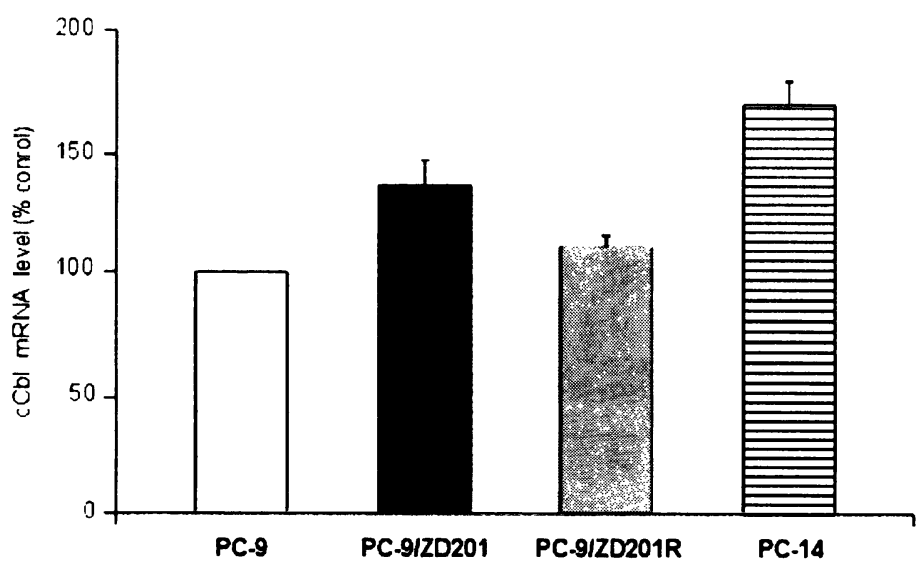

Fig. 7. Expression of c-Cbl mRNA in gefitinib-resistant cell lines Expression of c-Cbl mRNA was measured by quantitative PCR. $\beta$-actin was the internal-control primer. Data represents mean \pm SD (bar) of three separate experiments. Statistical differences were calculated by ANOVA with Fisher's protected least significant difference test.

degradation ${ }^{19}$. Due to these observations, EGF-internalization and -degradation activities were thought to represent EGF-EGFR complex turnover. In conclusion, internalization and degradation activities of the EGF-EGFR complex were enhanced in intrinsic- and acquired-gefitinib resistant cell lines.

\section{Expression of $c$-Cbl $m R N A$}

Recent studies using an in vitro ubiquitylation system have uncovered the role of c-Cbl protein, an E3 ubiquitin ligase that binds ligand-activated EGFR and enhances ubiquitylation of EGFR $^{10,20)}$. Since EGF-EGFR complex degradation activities were increased in gefitinib-resistant cells, the expression of c-Cbl mRNA was measured in these cell lines using real-time PCR analysis. In accordance with the results of EGFinternalization and -degradation activity analysis, the expression of c-Cbl mRNA was significantly increased in PC-9/ZD201 cells compared with the parent cells and this increase was less in the revertant cells (Fig. 7). In PC-14 cells, the expression of c-Cbl mRNA was about 1.7-fold higher than that in PC-9 cells.

\section{Discussion}

In this study, acquired gefitinib-resistant NSCLC cell lines were established to examine the mechanisms of resistance to gefitinib. Parental PC-9 cells were initially exposed to 10 $\mathrm{nM}$ of gefitinib, and the dose was gradually increased. PC-9 cells acquired gefitinib resistance slowly, and after about 6 months of drug exposure parental cells could survive in medium containing $200 \mathrm{nM}$ gefitinib; these resistant cells were named PC-9/ZD201. Interestingly, gefitinib resistance was not permanent, and after 6 months of culturing in drug-free conditions, PC-9/ZD201 cells gradually became less resistant to gefitinib until, finally, sensitivity to gefitinib was completely restored and a revertant cell line (PC-9/ ZD201R) was established. There were no differences in EGFR mRNA sequence between PC-9 and PC-9/ZD201 cell lines (data not shown). 
It has been reported that acquired resistance against some anticancer drugs is caused by a decrease in the expression and activity of the drug's target ${ }^{21,22)}$. Contrary to these reports, Viloria-Petit et al reported that overexpression of vascular endothelial growth factor (VEGF) caused resistance to anti-EGFR monoclonal antibody, C225, in a human epidermoid carcinoma A431 xenograft model $^{23)}$. In order to elucidate whether the expression of the gefitinib target molecule, EGFR, contributed to resistance, the levels of EGFR mRNA and protein were measured. In the resistant cells, EGFR mRNA and protein expression were significantly decreased compared to the parental PC-9 cell line. Although EGFR mRNA expression was still low in the revertant PC-9/ZD201R, protein expression partially recovered. These results were reflected in the ligand binding activity assay. ${ }^{125}$ I-EGF binding activity in PC-9/ZD201 was decreased to $63 \%$ of that in PC-9 and this activity was partially restored to $78 \%$ in PC-9/ZD201R (Fig. 5). EGFR protein expression levels correlated with sensitivity to gefitinib and the decrease in EGFR protein expression is one of the factors involved in gefitinib-acquired resistance in PC-9/ZD201 cells.

To explain the discrepancy between EGFR mRNA and protein expression in PC-9/ ZD201R, we considered the effect of the EGFR-degradation pathway. EGFR-protein expression was significantly decreased by ligand exposure in PC-9/ZD201 (Fig. 4a). Down-regulation of EGFR was observed in part in PC-9/ZD201R but not in PC-9. Because this down-regulation was inhibited by gefitinib and lactacystin, the phenomenon was thought to be related to EGFR autophosphorylation and the lysosomal degradation pathway. Ligand-induced activation of EGFR leads to activation of downstream signaling pathways and also to rapid endocytosis ${ }^{24}$. The endocytic receptors can be targeted to the lysosome for degradation, which terminates receptor signals ${ }^{25-27)}$. As expected, EGFR-internalization and -degradation pathways were relatively activated in PC-9/ZD201 cells compared with PC-9 (Fig. 6a, b). These pathways were restored to normal levels in the revertant cells, suggesting that down-regulation of EGFR mRNA and activation of EGFR degradation mediates the down-regulation of EGFR protein in PC-9/ZD201 compared with PC-9. Although mRNA down-regulation was sustained, the decreased level of EGFR-degradation might cause EGFR protein up-regulation in PC-9/ZD201R cells. There were no differences in the inhibitory effect of gefitinib on EGFR degradation in PC-9, PC-9/ZD201, and PC9/ZD201R cells (Fig. 6c). EGFR degradation was also enhanced in intrinsic gefitinibresistant PC-14 cells (about 5-fold more than in PC-9), suggesting that increased EGFR degradation activity is involved in both intrinsic- and acquired-resistant mechanisms to gefitinib.

c-Cbl protein is a E3 ubiquitin ligase, which is recruited to the activated EGFR through binding to phosphorylated Tyr-1045 on EGFR and it subsequently mediates ubiquitylation and down-regulation of $\mathrm{EGFR}^{28,29)} \mathrm{A}$ recent study reported that $\mathrm{c}-\mathrm{Cb}$ l binding to EGFR was essential for the degradation of EGFR but not for the initial endocytosis step $^{30}$ ) c-Cbl mRNA expression was slightly increased in PC-9/ZD201 cells and restored in part in PC9/ZD201R whilst in PC-14, c-Cbl mRNA was significantly higher than in PC-9. This suggests that up-regulation of this protein may contribute to gefitinib resistance. Further study is needed to clarify the role of the EGFR-degradation pathway and c-Cbl in the development of acquired gefitinib-resistance.

In this paper, we have reported on an acquired gefitinib-resistant cell line, which was 
established at relatively early time after gefitinib exposure. We have also established several gefitinib-resistant cell lines and a revertant cell line after more than 1 year of drug exposure. With long-term exposure, the characteristics of the gefitinib-resistant cells have been moderately altered. In the resistant cell line named PC-9/ZD2001 the expression of EGFR mRNA and protein was significantly decreased as in PC-9/ZD201 cells, but ligand-mediated EGFR-degradation was generally not observed in this cell line (data not shown, submitted for publication). Since EGFR signaling was dissociated from ERK phosphorylation in this cell line, it is possible that down-stream molecules in the EGFR signaling pathway might have been modified during long-term drug exposure. This suggests that multiple factors may be involved in the development of acquired gefitinib resistance particularly during continuous long-term drug exposure.

In summary, acquired gefitinib resistance, which developed at an early time of drug exposure, correlated with decreased EGFR expression with the EGFR degradation pathway contributing to this down-regulation.

('Iressa' is a trademark of the AstraZeneca group of companies)

\section{Acknowledgements}

This work was supported in part by a Grant-in-aid for the High-Technology Research Center Project from the Ministry of Education, Science, Sports and Culture of Japan, a Showa University Grant-in-Aid for Innovative Collaborative Research Projects and by a Special Research Grant-in Aid for Development of Characteristic Education from the Japanese Ministry of Education, Culture, Sports, Science and Technology of Japan.

\section{References}

1) Wells A : EGF receptor. Int J Biochem Cell Biol 31 : 637-643 (1999)

2) Yarden $Y$ : The EGFR family and its ligands in human cancer. Signalling mechanisms and therapeutic opportunities. Eur J Cancer 37(Suppl 4) : S3-8 (2001)

3) Prenzel N, Fischer OM, Streit S, Hart $\mathbf{S}$ and Ullrich $\mathbf{A}$ : The epidermal growth factor receptor family as a central element for cellular signal transduction and diversification. Endocr Relat Cancer 8 : 11-31 (2001)

4) Sartor CI: Biological modifiers as potential radiosensitizers: targeting the epidermal growth factor receptor family. Semin Oncol $27: 15-20$, discussion $92-100$ (2000)

5) Wosikowski K, Silverman JA, Bishop P, Mendelsohn J and Bates SE : Reduced growth rate accompanied by aberrant epidermal growth factor signaling in drug resistant human breast cancer cells. Biochim Biophys Acta 1497 : 215-226 (2000)

6) Chen Z, Ke LD, Yuan XH and Adler-Storthz K : Correlation of cisplatin sensitivity with differential alteration of EGFR expression in head and neck cancer cells. Anticancer Res $20: 899-902$ (2000)

7) Akimoto T, Hunter NR, Buchmiller L, Mason K, Ang KK and Milas L: Inverse relationship between epidermal growth factor receptor expression and radiocurability of murine carcinomas. Clin Cancer Res $\mathbf{5}$ : 2884-2890 (1999)

8) de Melker AA, van der Horst G, Calafat J, Jansen $\mathbf{H}$ and Borst J : c-Cbl ubiquitinates the EGF receptor at the plasma membrane and remains receptor associated throughout the endocytic route. J Cell Sci $114: 2167-$ $2178(2001)$

9) Levkowitz G, Waterman H, Zamir E, Kam Z, Oved S, Langdon WY, Beguinot L, Geiger B and Yarden Y : c-Cbl/Sli-1 regulates endocytic sorting and ubiquitination of the epidermal growth factor receptor. Genes Dev 12 : 3663-3674 (1998)

10) Joazeiro CA, Wing SS, Huang H, Leverson JD, Hunter T and Liu YC: The tyrosine kinase negative regulator c-Cbl as a RING-type, E2-dependent ubiquitin-protein ligase. Science 286 : 309-312 (1999)

11) Waterman H, Levkowitz G, Alroy I and Yarden Y : The RING finger of $\mathrm{c}-\mathrm{Cbl}$ mediates desensitization of the epidermal growth factor receptor. J Biol Chem 274 : 22151-22154 (1999)

12) Wells A, Welsh JB, Lazar CS, Wiley HS, Gill GN and Rosenfeld MG : Ligand-induced transformation by a noninternalizing epidermal growth factor receptor. Science 247 : 962-964 (1990) 
13) Herbst RS : Dose-comparative monotherapy trials of ZD1839 in previously treated non-small cell lung cancer patients. Semin Oncol 30 : 30-38 (2003)

14) Fukuoka M, Yano S, Giaccone G, Tamura T, Nakagawa K, Douillard JY, Nishiwaki Y, Vansteenkiste J, Kudoh S, Rischin D, Eek R, Horai T, Noda K, Takata I, Smit E, Averbuch S, Macleod A, Feyereislova A, Dong RP and Baselga $\mathrm{J}$ : Multi-institutional randomized phase II trial of gefitinib for previously treated patients with advanced non-small-cell lung cancer. J Clin Oncol 21 : 2237-2246 (2003)

15) Kris MG, Natale RB, Herbst RS, Lynch TJ Jr, Prager D, Belani CP, Schiller JH, Kelly K, Spiridonidis H, Sandler A, Albain KS, Cella D, Wolf MK, Averbuch SD, Ochs JJ and Kay AC: Efficacy of gefitinib, an inhibitor of the epidermal growth factor receptor tyrosine kinase, in symptomatic patients with non-small cell lung cancer: a randomized trial. JAMA $290: 2149-2158$ (2003)

16) Sorkin A, Di Fiore PP and Carpenter G : The carboxyl terminus of epidermal growth factor receptor/erbB-2 chimerae is internalization impaired. Oncogene $8: 3021-3028$ (1993)

17) Kornilova E, Sorkina T, Beguinot L and Sorkin A : Lysosomal targeting of epidermal growth factor receptors via a kinase-dependent pathway is mediated by the receptor carboxyl-terminal residues 1022-1123. J Biol Chem 271 : 30340-30346 (1996)

18) Barkan RS, Sorkin AD and Nikol'skii NN : Endocytosis and intracellular transport of epidermal growth factor after destruction of the actin cytoskeleton by cytochalasin B. Tsitologiia 30 : 1311-1317 (1988)

19) Ceresa BP and Schmid SL: Regulation of signal transduction by endocytosis. Curr Opin Cell Biol 12 : 204-210 (2000)

20) Levkowitz G, Waterman H, Ettenberg SA, Katz M, Tsygankov AY, Alroy I, Lavi S, Iwai K, Reiss Y, Ciechanover A, Lipkowitz S and Yarden Y: Ubiquitin ligase activity and tyrosine phosphorylation underlie suppression of growth factor signaling by c-Cbl/Sli-1. Mol Cell 4 : 1029-1040 (1999)

21) Kijima T, Kubota $\mathbf{N}$ and Nishio $\mathrm{K}$ : Establishment of a CPT-11-resistant human ovarian cancer cell line. Anticancer Res 14 : 799-803 (1994)

22) Ferguson PJ, Fisher MH, Stephenson J, Li DH, Zhou BS and Cheng YC: Combined modalities of resistance in etoposide-resistant human KB cell lines. Cancer Res 48 : 5956-5964 (1988)

23) Viloria-Petit A, Crombet T, Jothy S, Hicklin D, Bohlen P, Schlaeppi JM, Rak J and Kerbel RS : Acquired resistance to the antitumor effect of epidermal growth factor receptor-blocking antibodies in vivo: a role for altered tumor angiogenesis. Cancer Res 61 : 5090-5101 (2001)

24) Vieira AV, Lamaze C and Schmid SL: Control of EGF receptor signaling by clathrin-mediated endocytosis. Science 274 : 2086-2089 (1996)

25) Herbst JJ, Opresko LK, Walsh BJ, Lauffenburger DA and Wiley HS : Regulation of postendocytic trafficking of the epidermal growth factor receptor through endosomal retention. J Biol Chem 269 : 12865-12873 (1994)

26) Beguinot L, Lyall RM, Willingham MC and Pastan I : Down-regulation of the epidermal growth factor receptor in KB cells is due to receptor internalization and subsequent degradation in lysosomes. Proc Natl Acad Sci USA 81 : 2384-2388 (1984)

27) Futter CE, Pearse A, Hewlett LJ and Hopkins CR: Multivesicular endosomes containing internalized EGF-EGF receptor complexes mature and then fuse directly with lysosomes. J Cell Biol 132: 1011-1023 (1996)

28) Levkowitz G, Klapper LN, Tzahar E, Freywald A, Sela M and Yarden Y: Coupling of the c-Cbl protooncogene product to ErbB-1/EGF-receptor but not to other ErbB proteins. Oncogene 12:1117-1125 (1996)

29) Waterman H, Katz M, Rubin C, Shtiegman K, Lavi S, Elson A, Jovin T and Yarden Y: A mutant EGF-receptor defective in ubiquitylation and endocytosis unveils a role for Grb2 in negative signaling. EMBO J 21 : 303-313 (2002)

30) Duan L, Miura Y, Dimri M, Majumder B, Dodge IL, Reddi AL, Ghosh A, Fernandes N, Zhou P, Mullane-Robinson K, Rao N, Donoghue S, Rogers RA, Bowtell D, Naramura M, Gu H, Band V and Band $\mathrm{H}$ : Cbl-mediated ubiquitinylation is required for lysosomal sorting of epidermal growth factor receptor but is dispensable for endocytosis. J Biol Chem 278 : 28950-28960 (2003)

[Received February 5, 2004 : Accepted February 17, 2004] 